\title{
Identifikasi Kemampuan Berpikir Logis Mahasiswa Calon Guru Fisika Menggunakan Instrument TOLT
}

\author{
R Rahmawati ${ }^{1 *}$, Edy Kurniawan', A. Muafiah Nur ${ }^{2}$ \\ ${ }^{1}$ Program Studi Pendidikan Fisika, FKIP Universitas Muhammadiyah Makassar \\ ${ }^{2}$ Program Studi Pendidikan Guru Sekolah Dasar, FKIP Universitas Muhammadiyah Makassar \\ *Email: rahmawatisyam@unismuh.ac.id
}

Received: 12 Mei 2021; $\quad$ Accepted: 19 Juni 2021;

DOI: http://dx.doi.org/10.29303/jpft.v7i1.2719

Published: 20 Juni 2021

\begin{abstract}
This study aimed to identify the type of reasoning and the level of prospective physics teacher students' logical thinking ability. This type of research was a field study with a quantitative descriptive method. The test was the technique used in collecting data of this study. The instrument used in this study was the standard test like Test of Logical Thinking (TOLT). This test consists of 10 questions that measured five types of reasoning, namely proportional reasoning, variable control, probabilistic reasoning, correlation reasoning, and combination reasoning. The level of logical thinking ability was distinguished into concrete, transitional, and formal thinking operational. The sample of this study was students of physics teacher candidates at the first-year level, totaling 30 students. All of data was analyzed by quantitative descriptive. In general, students tend to the type of proportional reasoning and controlling variables and less on probabilistic reasoning. Based on the level of logical thinking ability, the results showed that the percentage of 30 students who were in the concrete, transitional, and formal categories, respectively, were $30 \%, 30 \%$, and $60 \%$. This data becomes the basis for consideration in the development of learning models and learning assessments used in lectures, especially in Department of Physics Education in one of the University in Makassar city, so that they are able to contribute to the development of students' level of logical thinking skills as a provision for the next life.
\end{abstract}

Keywords: Logical Thinking Skill; Reasoning; TOLT

\section{PENDAHULUAN}

Penalaran (reasoning) merupakan komponen yang memiliki peranan penting dalam setiap tahapan proses berpikir dasar dan berpikir kompleks (Krulik \& Rudnick, 1995). Lawson (1995) membedakan bentuk penalaran (reasoning) ke dalam dua mode, yaitu berpikir analogi (analogical thinking) dan berpikir logis (logical thinking). Berdasarkan hierarki tingkatan berpikir dan keterkaitannya dengan penalaran (reasoning), maka berpikir logis ikut berkontribusi dalam setiap tahapan berpikir kompleks mahasiswa sebagai individu pebelajar (Inhelder \& Piaget, 1959; Lawson, 1995).

Berpikir logis (logical thinking) merupakan salah satu bentuk penalaran dalam hierarki tingkatan berpikir. Peranan kedudukan kemampuan berpikir logis sangat membantu dalam menemukan suatu kebenaran berdasarkan aturan, pola atau logika tertentu yang diperlukan dalam menyelesaikan masalah (Krulik \& Rudnick, 1995).

Logical thinking atau pemikiran logis merupakan konsep Piaget (Piaget \& Inhelder, 2013) dan mengacu pada kemampuan seseorang dalam menggunakan penalaran operasional formal dan konkrit (Karplus \& Butts, 1977; Lawson \& Renner, 1975). Logical thinking menyertakan lima mode kemampuan penalaran yaitu kemampuan penalaran proporsional, pengontrolan variabel, penalaran probabilitas, penalaran korelasional, dan penalaran kombinatorial (Tobin \& Capie, 1981). Penalaran proporsional cukup penting dalam aspek kuantitatif, terutama untuk memahami derivasi dan penggunaan sejumlah besar hubungan fungsional, seperti pengembangan dan interpretasi data tabulasi 
dan grafik. Penalaran korelasional memiliki peranan penting dalam perumusan hipotesis dan interpretasi data yang perlu mempertimbangkan hubungan antar variabel. Pengontrolan variabel berperan penting dalam perencanaan, pelaksanaan dan interpretasi. Penalaran probabilitas berperan penting dalam interpretasi data dari temuan, pengamatan, atau percobaan. Penalaran kombinatorial dibutuhkan dalam perumusan hipotesis alternatif untuk menguji efek dari variabel yang dipilih (Tobin \& Capie, 1981; Lawson, 1995; Inhelder \& Piaget, 1959).

Kemampuan berpikir logis merupakan faktor internal dalam menentukan prestasi akademik dan kesuksesan peserta didik mengkonstruksi konsep-konsep sains. Peserta didik dengan kemampuan berpikir logis tinggi mampu memahami konsep-konsep sains dengan baik, mampu mengkonstruksi konsepsi alternatifnya dengan lebih mudah, dan sukses dalam menghadapi berbagai bentuk permasalahan (Tobin \& Capie, 1950, 1981,1982).

Salah satu tujuan pembelajaran sains adalah meningkatkan kemampuan berpikir logis peserta didik pada setiap jenjang pendidikan. Kemampuan berpikir logis merupakan variabel kognitif yang penting dipertimbangkan dalam mendesain pembelajaran sains dengan tujuan agar peserta didik sukses dalam membangun pengetahuan dan memiliki bekal sejumlah keterampilan serta kemampuan menghadapi berbagai permasalahan. Kemampuan berpikir logis diperlukan dalam pembelajaran sains sebab karakteristik aktifitas pembelajaran sains bersifat scientific (ilmiah) sehingga dominan membutuhkan keterampilan intelektual. Beberapa aktifitas ilmiah dalam pembelajaran sains seperti mengamati, mengklasifikasi, mengumpulkan data, menganalisis data, menginterpretasikan data, mengontrol dan mendefinisikan variabelvariabel secara operasional (Tobin \& Copie, 1982).

Uraian di atas memberikan dasar pemahaman tentang peranan dan fungsi variabel kemampuan berpikir logis dalam pembelajaran sains (fisika). Berdasarkan hal tersebut, maka penting dilakukan kajian awal terkait identifikasi tingkat kemampuan berpikir logis mahasiswa fisika sebagai dasar pertimbangan dalam merancang model pembelajaran dan pemilihan serta penggunaan jenis asesmen pembelajaran.

\section{METODE PENELITIAN}

Penelitian ini merupakan jenis penelitian study lapangan (field study) dengan menggunakan metode penelitian deskriptif kuantitatif untuk menggambarkan tingkatan kemampuan berpikir logis mahasiswa calon guru fisika tingkatan pertama sebagai sampel dalam penelitian ini yang berjumlah 30 mahasiswa yang diambil secara keseluruhan satu kelas dengan teknik purposive random sampling yang mana sebagai populasinya yaitu seluruh mahasiswa calon guru fisika. Pelaksanaan penelitian ini berlangsung pada tahun 2019/2020 semester genap di Program Studi Pendidikan Fisika di salah satu perguruan tinggi di kota Makassar.

Teknik pengumpulan data dilakukan melalui tes dengan menggunakan instrumen tes standar yang telah dikembangkan oleh Tobin \& Capei (1981). Tes ini merupakan instrument tes standar yang valid dan reliabel dengan nilai koefisien reliabilitas $(\alpha)=0.85$, kategori signifikansi tinggi $(p<0.0001)$, nilai mean $(M)=2.94$, dan standar deviasi $(\mathrm{SD})=2.94$. Instrumen tes TOLT ini terdiri dari 10 butir soal yang mewajibkan setiap peserta memilih jawaban yang dianggap paling tepat dan memilih pilihan alasan dari pilihan jawaban yang dipilih serta memberikan pilihan tingkat keyakinan atas 
pilihan alasan terhadap jawaban yang dipilih.

Setiap butir soal diberi skor 1 apabila pilihan jawaban tepat dan skor 0 apabila pilihan jawaban salah. Skor maksimal sebesar 10 dan skor minimal 0. Seluruh butir soal instrument TOLT tersebut mengukur lima tipe penalaran dengan uraian yaitu penalaran proporsional (butir soal 1 dan 2), pengontrolan variabel (butir soal 3 dan 4), penalaran probabilistik (butir soal 5 dan 6), penalaran korelasional (butir soal 7 dan 8), dan penalaran kombinatorial (butir soal 9 dan 10).

Tingkat kemampuan berpikir logis mahasiswa dikategorisasikan berdasarkan perolehan skor. Kategorisasi kemampuan berpikir logis dibedakan atas tiga jenis, yaitu konkret, transitional, dan kategori formal. Mahasiswa yang memperoleh skor 0-1 dikategorikan operasional konkret, skor 2-3 adalah kategori operasional transisional, dan mahasiswa yang memperoleh skor 4 ke atas dikategorikan operasional formal (Tobin \& Copie, 1982). Analisis lebih lanjut yaitu menentukan persentase mahasiswa berdasarkan pada lima tipe penalaran, yaitu penalaran proporsional, pengontrolan variabel, penalaran probabilitas, penalaran korelasional, dan penalaran kombinatorial. (Tobin \& Capie, 1981)

\section{HASIL DAN PEMBAHASAN}

Berikut ini adalah uraian hasil penelitian terkait tingkat kemampuan berpikir logis mahasiswa calon guru fisika pada tingkatan pertama yang diperoleh berdasarkan skor tes TOLT.

\section{Hasil}

Hasil perolehan skor tes TOLT mahasiswa calon guru fisika tingkatan pertama dijabarkan berdasarkan lima tipe penalaran seperti yang ditunjukkan pada Tabel 1.
Tabel 1. Skor tes TOLT Mahasiswa pada masing-masing Tipe Penalaran

\begin{tabular}{lccc}
\hline Tipe Penalaran & $\begin{array}{c}\text { Total } \\
\text { Skor } \\
(N)\end{array}$ & $\begin{array}{c}\text { Mean } \\
(\mu)\end{array}$ & $\begin{array}{c}\text { Standar } \\
\text { Deviasi } \\
(S D)\end{array}$ \\
\hline $\begin{array}{l}\text { Penalaran } \\
\text { Proporsional } \\
\text { Pengontrolan }\end{array}$ & 32 & 1,07 & 0,87 \\
$\begin{array}{l}\text { Variabel } \\
\text { Penalaran }\end{array}$ & 25 & 0,83 & 0,87 \\
$\begin{array}{l}\text { Probabilistik } \\
\text { Penalaran }\end{array}$ & 4 & 0,13 & 0,35 \\
$\begin{array}{l}\text { Korelasional } \\
\text { Penalaran } \\
\text { Kombinatorial }\end{array}$ & 14 & 0,47 & 0,51 \\
\hline $\begin{array}{l}\text { Keseluruhan } \\
\text { Penalaran }\end{array}$ & 89 & 2,97 & 2,13 \\
\hline
\end{tabular}

Tabel 1 menunjukkan bahwa mahasiswa calon guru Fisika pada tingkatan pertama memperoleh skor tertinggi pada tipe penalaran proporsional $(\mathrm{N}=32)$ dan terendah pada tipe penalaran probabilistik $(\mathrm{N}=4)$. Sementara, skor yang sama pada tipe penalaran korelasional dan kombinatorial. Data ini menunjukkan bahwa mahasiswa calon guru fisika tingkatan pertama berkembang dengan baik pada tipe penalaran proporsional dan minim pada tipe penalaran probabilistik serta berimbang pada kemampuan penalaran tipe korelasional dan kombinatorial. Berdasarkan data Tabel 1 dapat disimpulkan bahwa kecenderungan tipe penalaran mahasiswa yang berkembang dengan baik bervariasi antara individu yang satu dengan lainnya. Meskipun demikian, setiap tipe penalaran masing-masing memberikan kontribusi pada capaian prestasi akademik. Penalaran proporsional penting dalam aspek pengembangan dan interpretasi data tabulasi dan grafik. Penalaran korelasional berperan penting dalam perumusan hipotesis dan interpertasi data yang perlu mempertimbangkan hubungan antar variabel. Pengontrolan variabel penting dalam perencanaan, pelaksanaan, dan interpretasi. Sementara, penalaran kombinatorial terjadi dalam perumusan hipotesis alternative untuk menguji efek variabel yang dipilih (Wiji dkk., 2014). Oleh karena itu, proses pembelajaran 
fisika penting membekalkan pengembangan seluruh tipe penalaran mahasiswa yang bermuara pada peningkatan kemampuan berpikir logis mahasiswa agar berada pada kategori operasional formal.

Analisis lebih lanjut terkait kategori tingkat kemampuan berpikir logis terangkum pada Tabel 2.

Tabel 2. Kategorisasi Tingkat Kemampuan Berpikir Logis Mahasiswa Calon Guru Fisika Tingkatan Pertama

\begin{tabular}{ccc}
\hline Rentang Skor & $\begin{array}{c}\text { Kategori } \\
\text { Kemampuan } \\
\text { Berpikir Logis }\end{array}$ & $\begin{array}{c}\text { Jumlah } \\
\text { Mahasiswa } \\
(\%)\end{array}$ \\
\hline $0-1$ & Konkret & 30 \\
$2-3$ & Transisional & 40 \\
$4-10$ & Formal & 30 \\
\hline
\end{tabular}

Kategori tingkat kemampuan berpikir logis mahasiswa seperti yang ditunjukkan pada Tabel 2 menunjukkan bahwa tingkat kemampuan berpikir logis mahasiswa terdistribusi secara merata pada operasional konkret, transisional, maupun formal. Hal ini menunjukkan bahwa kemampuan berpikir logis pada opearsional formal belum sepenuhnya dimiliki oleh seluruh mahasiswa calon guru fisika tingkatan pertama. Temuan ini bertentangan dengan teori Inhelder \& Piaget (1959) terkait perkembangan kognitif yang seharusnya pada usia mahasiswa tersebut (19-20 tahun) sudah semestinya berada pada kategori berpikir formal. Lebih lanjut, data nilai mean skor tes seluruh tipe penalaran seperti yang ditunjukkan pada Tabel 2 menunjukkan bahwa mahasiswa calon guru fisika tingkatan pertama berada pada tipe operasional transisional.

\section{Pembahasan}

Hasil penelitian menunjukkan bahwa penalaran proporsional memiliki skor rata-rata yang paling tinggi $(M=1,07)$ sedangkan penalaran probabilitas memiliki skor rata-rata paling rendah $(M=0,13)$. (Wiji et al., 2014) menunjukkan hasil penelitian yang sama yaitu skor penalaran proporsional paling tinggi dan skor terendah pada penalaran probabilitas. Hasil penelitian sama juga ditemukan pada Fah (2009) yang menunjukkan bahwa skor penalaran proporsional paling tinggi dan skor terendah pada penalaran probabilitas. Rendahnya kemampuan mahasiswa pada penalaran probablititas dan tinggi pada jenis penalaran lain menunjukkan bahwa perkembangan jenis penalaran setiap mahasiswa tidak sama dan tentunya bergantung pada lingkungan hidup yang membentuk mahasiswa tersebut (Fah, 2009; Wiji, 2014; Yenilmez dkk., 2006). Hasil penelitian lebih lanjut menunjukkan bahwa persentase tertinggi kemampuan berpikir logis mahasiswa berada pada kategori operasional transisional. Temuan ini bertentangan dengan teori perkembangan kognitif yang dikemukakan oleh Piaget (Piaget \& Inhelder, 2013). Hasil penelitian ini juga menunjukkan bahwa belum maksimalnya kemampuan berpikir logis mahasiswa pada kategori operasional formal juga dipengaruhi oleh lingkungan pembelajaran mahasiswa. Artinya, proses perkuliahan belum memberikan kontribusi secara maksimal dalam mengembangkan kemampuan berpikir logis mahasiswa calon guru fisika. Handayani dkk. (2020) menunjukkan hasil penelitian yang serupa bahwa persentase tertinggi mahasiswa berada pada kategori operasional transisional.

Telah diuraikan sebelumnya bahwa kemampuan berpikir logis memiliki kontribusi utama terhadap keberhasilan prestasi akademik mahasiswa calon guru fisika. Tsitsipis dkk. (2010) dalam penelitiannya mencoba melihat pengaruh tiga variabel kognitif, salah satunya adalah kemampuan berpikir logis terhadap tingkat penguasaan konsep pada materi sifat alami materi dan zat serta perubahannya. Salah satu kesimpulan hasil penelitian tersebut adalah tingkat kemampuan berpikir logis formal lebih unggul dalam menguasai materi dibandingkan mahasiswa dengan kemampuan 
berpikir konkret dan transisional. Sejalan dengan hal tersebut, Oliva (2003) dalam penelitiannya mengungkapkan bahwa mahasiswa dengan tingkat kemampuan berpikir logis yang tinggi dapat dengan mudah mengubah konsepsi alternatifnya untuk digunakan dalam memikirkan dan menemukan jawaban suatu permasalahan.

Selama proses pembelajaran, mahasiswa melibatkan serangkaian proses bernalarnya dalam mengenali situasi-situasi baru dan menghubungkan situasi-situasi baru tersebut dengan situasi lama yang telah ada pada diri mereka. Artinya, kemampuan bernalar individu memiliki konstribusi bagi kesuksesan dan prestasi belajar mahasiswa (Tsitsipis et al., 2010). Mahasiswa dengan tingkat kemampuan berpikir logis yang tinggi dapat dengan mudah mengubah konsepsi alternatifnya (Wiji, 2014). Dengan adanya urutan fase pembelajaran dalam perkuliahan kelistrikan dan kemagnetan, tentunya hal tersebut dapat membangun hubungan logis antar berbagai konsep fisika sehingga akan meningkatkan kemampuan berpikir logis (BouJaoude, dkk. 2004; K.G. Tobin \& Copie, 1982).

(Yenilmez et al., 2007) dalam penelitiannya menemukan hubungan antara prestasi akademik peserta didik dengan kemampuan berpikir logis, pengetahuan awal, dan perbedaan gender. Hasil penelitian menunjukkan terdapat perbedaan yang signifikan antara peserta didik dengan kemampuan berpikir logis rendah dan peserta didik dengan kemampuan tinggi terhadap prestasi akademik. Selain itu, temuan lain dalam penelitian tersebut menunjukkan bahwa kemampuan berpikir logis, pengetahuan awal, dan perbedaan gender merupakan prediktor yang signifikan mempengaruhi prestasi akademik peserta didik pada materi subjek fotosintesis dan respirasi pada tanaman. (BouJaoude et al., 2004) dalam penelitiannya membandingkan kinerja peserta didik pada masalah kimia konseptual dan kimia algoritmik. Hasil penelitian menunjukkan bahwa secara signifikan peserta didik dengan skor kemampuan berpikir logis yang tinggi memiliki kemampuan lebih baik dibandingkan peserta didik dengan skor kemampuan berpikir logis rendah dalam menyelesaikan masalah kimia konseptual. Akan tetapi, tidak terdapat perbedaan signifikan antara individu dengan kemampuan berpikir logis tinggi dan individu dengan kemampuan berpikir logis rendah dalam menyelesaikan masalah kimia algoritmik. Lebih lanjut, penelitian yang dilakukan oleh (Rowell et al., 1985) menunjukkan bahwa variabel kemampuan berpikir logis sangat penting bagi peserta didik dalam mencapai kesuksesan belajar sains sehingga penting bagi pendidik menyadari terkait bentuk-bentuk penalaran peserta didik dan berbagai tuntutan kognitif terkait konten pembelajaran, sehingga diharapkan agar para pendidik (termasuk dosen) secara optimal menyesuaikan konten materi pembelajaran dengan penggunaan strategi pengajaran terhadap kemampuan peserta didik.

Uraian di atas memberikan suatu kesimpulan bahwa proses pembelajaran melalui serangkaian mata kuliah-mata kuliah program studi Pendidikan Fisika perlu dirancang mampu membekalkan kemampuan berpikir logis mahasiswa secara bertahap dan berkelanjutan. Dengan kata lain, diperlukan suatu inovasi model pembelajaran dan teknik asesmen pembelajaran yang bersesuaian yang dapat mengembangkan kemampuan berpikir logis mahasiswa. Dengan demikian, mahasiswa dengan mudah mampu memecahkan berbagai persoalan yang dijumpai dalam kondisi dan situasi apapun. 


\section{PENUTUP}

Hasil penelitian menunjukkan bahwa terdapat dua tipe penalaran mahasiswa calon guru fisika tingkat pertama yang berkembang dengan baik, yaitu penalaran proporsional dan pengontrolan variabel. Sementara, tiga tipe penalaran yang lain masih perlu upaya pengembangannya melalui pembekalan perkuliahan. Lebih lanjut, temuan penelitian mengungkapkan bahwa kemampuan berpikir logis mahasiswa calon guru fisika tingkat pertama secara umum berkembang pada operasional transisional. Berdasarkan hasil penelitian ini, perlu suatu upaya rancangan inovasi pembelajaran dan teknik asesmen yang mampu membantu pengembangan kemampuan berpikir logis agar seluruh mahasiswa berada pada kategori operasional formal.

\section{UCAPAN TERIMAKASIH}

Peneliti mengucapkan banyak terimakasih pada Lembaga Penelitian, Pengembangan, dan Pengabdian Kepada Masyarakat (LP3M) Universitas Muhammadiyah Makassar atas dukungan anggaran penelitian yang diberikan dalam skema Hibah Penelitian Internal tahun anggaran 2019/2020. Ucapan terimakasih juga kepada seluruh sivitas akademik program studi Pendidikan Fisika FKIP Universitas Muhammadiyah Makassar atas dukungan sarana dan prasarana serta kerjasama yang baik dari kalangan mahasiswa calon guru fisika.

\section{REFERENSI}

BouJaoude, S., Salloum, S., \& Abd-ElKhalick, F. (2004). Relationships between selective cognitive variables and students' ability to solve chemistry problems. International Journal of Science Education, 26(1), 63-84. https://doi.org/10.1080/095006903200 0070315

Handayani, Windyariani, \& Pauzi. (2020).
Scientific Reasoning Profile of Senior High School Students on Ecosystem Subject. BIODIK: Jurnal Ilmiah Pendidikan Biologi, 6(2), 176-186.

Karplus, R., \& Butts, D. P. (1977). Science teaching and the development of reasoning. Journal of Research in Science Teaching, 14(2), 169-175. https://doi.org/10.1002/tea.366014021 2

Krulik, S., \& Rudnick, J. A. (1995). The New Sourcebook For Teaching Reasoning And Problem Solving In Junior And Senior High.

Lawson, A. E., \& Renner, J. W. (1975). Relationships of science subject matter and developmental levels of learners. Journal of Research in Science Teaching, 12(4), 347-358. https://doi.org/10.1002/tea.366012040 5

Lay, Y. F. (2009). Logical Thinking Abilities among Form 4 Students in the Interior Division of Sabah, Malaysia. Journal of Science and Mathematics Education in Southeast Asia, 32(2), 161-27; 187.

Oliva, J. M. (2003). The structural coherence of students' conceptions in mechanics and conceptual change. International Journal of Science Education, 25(5), 539-561.

https://doi.org/10.1080/095006902101 63242

Piaget, J., \& Inhelder. (2013). The Growth Of Logical Thinking From Childhood To Adolescence. In The Growth Of Logical Thinking From Childhood To Adolescence. Basis Book, Inc. https://doi.org/10.4324/978131500967 4

Rowell, J. A., Tobin, K., \& Swingler, D. G. (1985). Reasoning abilities of secondary school students aged 13-16 and implications for the teaching of science. European Journal of Science Education, 7(4), 387-397. https://doi.org/10.1080/014052885007 0407 
Tobin, K. G., \& Capie, W. (1980). Teaching Process Skills in the Middle School. School Science and Mathematics, $80(7)$, 590-600.

https://doi.org/10.1111/j.1949-

8594.1980.tb09745.x

Tobin, K. G., \& Capie, W. (1981). The development and validation of a group test of logical thinking. Educational and Psychological Measurement, 41(2), 413-423. https://doi.org/10.1177/001316448104 100220

Tobin, K. G., \& Capie, W. (1982). Relationships between formal reasoning ability, locus of control, academic engagement and integrated process skill achievement. Journal of Research in Science Teaching, 19(2), 113-121. https://doi.org/10.1002/tea.366019020 3

Tsitsipis, G., Stamovlasis, D., \& Papageorgiou, G. (2010). The effect of three cognitive variables on students' understanding of the particulate nature of matter and its changes of state. International Journal of Science Education, 32(8), 987-1016. https://doi.org/10.1080/095006909028 93605

Wiji. (2014). Pengembangan Desain Perkuliahan Kimia Sekolah Berbasis Model Mental untuk Meningkatkan Pemahaman Materi Subyek Mahasiswa Calon Guru Kimia. Universitas Pendidikan Indonesia.

Wiji, W., Liliasari, L., Sopandi, W., \& Martoprawiro, M. A. K. (2014). Kemampuan Berpikir Logis Dan Model Mental Kimia Sekolah Mahasiswa Calon Guru. Jurnal Cakrawala Pendidikan, 1(1), 147-156. https://doi.org/10.21831/cp.v1i1.1871

Yenilmez, A., Sungur, S., \& Tekkaya, C. (2006). Students' achievement in relation to reasoning ability, prior knowledge and gender. Research in Science \& Technological Education,
24(1), $129-138$. https://doi.org/10.1080/026351405004 85498

Yenilmez, A., Sungur, S., \& Tekkaya, C. (2007). reasoning ability, prior knowledge and Students ' achievement in relation to reasoning ability, prior knowledge. June 2015, 37-41. https://doi.org/10.1080/026351405004 85498 